\title{
Plant fitness assessment for wild relatives of insect resistant crops
}

\author{
Deborah K. LeTOURneAU* and Joy A. HAGEN \\ Department of Environmental Studies, University of California, Santa Cruz, CA 95064, USA
}

Risk assessments of new insect-resistant crops will need to estimate the potential for increased weediness of wild crop relatives as a consequence of gene flow. When field experiments are precluded by containment concerns, simulation experiments can identify hazards or measure expected differences between GMOs and parental plants. To measure plant fitness consequences of wild plant protection from Bt-susceptible herbivores, we used topical sprays of bacterial Bacillus thuringiensis larvacide (Bt) on Brassica rapa. Spontaneous crosses between $B$. rapa and $B t$ cole crops cannot be precluded, especially if adoption of $B t$ varieties leads to high exposure. We compared survivorship and seed output of $B$. rapa that were either protected from or exposed to $B t$-susceptible Lepidoptera in the various conditions where hybrids are likely to occur: cultivated (disked) soil, uncultivated agricultural field margins, and nearby non-crop habitats (meadows and ruderal areas). The relative effect of herbivore protection varied among years, habitats, and populations of seedlings. In 2003-2004, Bt sprays did not result in lower herbivory on B. rapa, and plant fitness was not increased. However, in 2004-2006 $B$. rapa seedlings protected from $B t$-susceptible herbivores lived $25 \%$ longer, on average, than those that were exposed to these herbivores. In addition, an average B. rapa seedling sprayed with $B$ throughout its lifetime was twice as likely to produce siliques and had $251 \%$ of the seed output of a seedling exposed to herbivores. The fitness advantage of Bt-based plant protection was apparent in 2004-2005 in half the plants that experienced higher herbivory, and for 2005-2006, was more pronounced in agricultural habitats than in meadows with established, perennial vegetation and less disturbance. Positive effects of Bt-based plant protection and greater fitness in disturbed habitats suggest that crop-wild gene flow may benefit weed populations, and that field tests with herbivore exclusion/addition experiments are feasible alternatives when molecular containment of transgenes restricts field experiments with insect resistant crop-wild hybrids.

Keywords: Brassica rapa / plant fitness / herbivory / Bt crops / wild relatives / genetically modified crops / risk assessment

\section{INTRODUCTION}

Environmental assessments used in the U.S. for deregulating corn, cotton and potato that express bacterial Bacillus thuringiensis $(B t)$ toxins cited a low risk of enhanced weediness in wild relatives because crop to wild transgene transfer is unlikely or restricted. Also, in these assessments, insect resistance was not recognized as a general trait of weedy plants (Clark, 2006; National Research Council, 2002; Parker and Kareiva, 1996). However, an assessment of the consequences of gene flow will be necessary in future deregulation decisions, because most of the major and minor crops in the world either exist in the wild themselves or hybridize with wild relatives somewhere in their range (Ellstrand, 2003; Ellstrand et al., 1999; Snow and Moran-Palma, 1997). A large number of vegetable, row, and tree crops have been transformed with $B t$ transgenes or other insect resistance (IR) traits.
Plants such as sunflower, oilseed rape, lettuce, and rice, for example, will be likely to hybridize with wild relatives in the United States; deregulation of such IR varieties will be based on evidence that the environmental consequences of gene flow will be acceptable or mitigatable. Despite previous arguments to the contrary in early environmental assessments, the potential for increased weediness is clearly of concern when wild crop relatives obtain an IR trait through gene flow and introgression (Colwell et al., 1985; Darmency, 1994; Hails, 2000; Hails and Morley, 2005; Hoffman, 1990; Kareiva et al., 1994; Snow et al., 2005; Tiedje, 1989; Wolfenbarger and Phifer, 2000). However, scant knowledge about the ecological factors that regulate the abundance, competitive ability, or geographic range of weeds still limits our ability to predict whether novel plant defenses are likely to increase the weediness of a particular wild crop relative (Snow et al., 2005).

* Corresponding author: dletour@ucsc.edu 
Studies identifying and quantifying hazards associated with gene flow are subject to methodological tradeoffs because of containment restrictions put in place to prevent the kind of potential hazard that the studies are designed to detect. Measurements of fitness parameters to assess weediness of crop-wild hybrids require flower and seed production. Therefore, reproductive isolation of transgenic plants must be achieved by male sterility, physical containment in cages, or by sowing transgenic plants at sites where wild relatives do not occur. Each of these manipulations may introduce differences from natural variation, or from habitat areas of concern for hybrid formation, in ways that confound the results of assessments for weediness characteristics, thereby reducing the relevance of such field tests. An alternative method, used in this study, is to conduct tests in the field, at sites where hybrids would be expected to occur spontaneously, but using herbivore protection/addition techniques on nontransgenic plants.

We present herbivore protection experiments using $B t$ sprays on wild mustard (Brassica rapa L.) as a method to assess potential fitness differences should crop transgenes from $B t$ cole crops (such as $B t$ oilseed rape, $B t$ cabbage, or $B t$ broccoli) introgress into wild populations of sexually compatible weeds. In coastal California, the flora surrounding cole crop fields includes naturalized cabbage plants (B. oleracea L.), wild radish (Raphanus sativus L.), wild mustards (B. rapa L., B. nigra L., and others), as well as native relatives. We compared relative levels of plant mortality, longevity, reproductive success, and total seed production per seedling of Bt-protected versus exposed wild mustard in the three main habitats where B. rapa occurs naturally: cultivated (disked) agricultural fields, uncultivated agricultural field margins, and nearby areas of unmanaged vegetation, including ruderal fragments and meadows (Fig. 1). Cultivated fields, disked to reduce weeds and loosen soil before planting crops, and agricultural field margins are commonly invaded by wild mustard. These habitats and nearby meadows and ruderal areas also differ in resources and vegetational quality, and may differ in patterns of gene flow, so that they represent the range of conditions under which wild relatives of $B t$ cole crops occur locally. The direction and size of differences in plant fitness are then compared to studies using various isolation methods, to gauge the usefulness of our approach in informing risk assessments and regulatory decision-making for $B t$ crops.

\section{RESULTS}

\section{Herbivory}

The difference in herbivore damage between $B t$-protected (topical sprays) plants and plants exposed to herbivores varied considerably in different years, and among habitats. In 2003-2004, B. rapa showed no significant difference in herbivory between protected and exposed plants with larval additions, with the average damage category per plant (using mean per plant, with categories $0(=0 \%)$, $1(=1-25 \%), 2(=25-50 \%)$, or $3(>50 \%)$ for each leaf) at $0.31 \pm 0.06 \mathrm{SE}$ and $0.45 \pm 0.10 \mathrm{SE}$, respectively. Damage ranged from zero to $29 \%$ leaf tissue removed per plant. Despite one or two Pieris rapae (2nd instar) larval additions per plant on exposed plants, ambient levels of herbivory in the field were too low to provide an appreciable herbivory treatment in this preliminary experiment. In 2004-2005, plant damage ranged from zero to $100 \%$ leaf tissue removed, but defoliation levels of over half of a plant's leaf area were rare, even at eight weeks after the first rain, when average levels of plant damage were highest in our study. The majority of plants, $62 \% \pm 8 \%$ of $B t$-sprayed seedlings and $45 \% \pm 8 \%$ of unprotected seedlings with added larvae, had either no damage or very low damage $(<5 \%$ of leaf area). However, topical $B t$ sprays reduced average levels of herbivore damage to foliage by half compared to plants that were not protected from $B t$-susceptible herbivores and inoculated monthly with a single $P$. rapae larva. Both herbivory treatment and habitat type were significant factors affecting herbivory on B. rapa seedlings in 2004-2005. Plants protected from $B t$-susceptible herbivores were $12.5 \%( \pm 1.6 \%)$ damaged, on average, vs. $29.3 \%( \pm 2.7 \%)$ of the foliage removed per plant, on average, plants sprayed with denatured $B t$ and inoculated once or twice (6 week old plants) with a $P$. rapae larva (SAS Logistic Regression, Wald $X^{2}=$ $37.2, \mathrm{df}=1, P<0.0001)$. Seedling damage was lowest, on average, in natural vegetation plots $(14.4 \% \pm 2.3 \%)$ compared to field margin $(26.0 \% \pm 3.4 \%)$ and disked $(22.3 \% \pm 2.9 \%)$ field plots (habitat type, $X^{2}=26.4$, df $=2, P<0.0001)$. However, we detected no significant herbivory treatment by habitat type interaction. As $B$. rapa plants bolted and produced flowers, mean damage levels per plant diminished to $5-10 \%$, and no longer showed any significant differences between exposed and protected plants nor among habitat types (logistic regression, $P>0.1$ ).

\section{Survivorship patterns}

Plant mortality rates were high overall in experimental plots, with the majority of plants (59\% in 2004-2005 and $81 \%$ in 2005-2006) dying before they had viable seeds. In 2005-2006, the average rate of seedling mortality $(21.5 \% \pm 2.7 \% \mathrm{SE})$ for exposed plants was significantly greater than the $14.6 \%( \pm 2.1 \% \mathrm{SE})$ of seedlings dying when protected by $B t$ sprays (logistic regression, df $=1, \mathrm{~F}=7.7, P=0.0054$ ). 


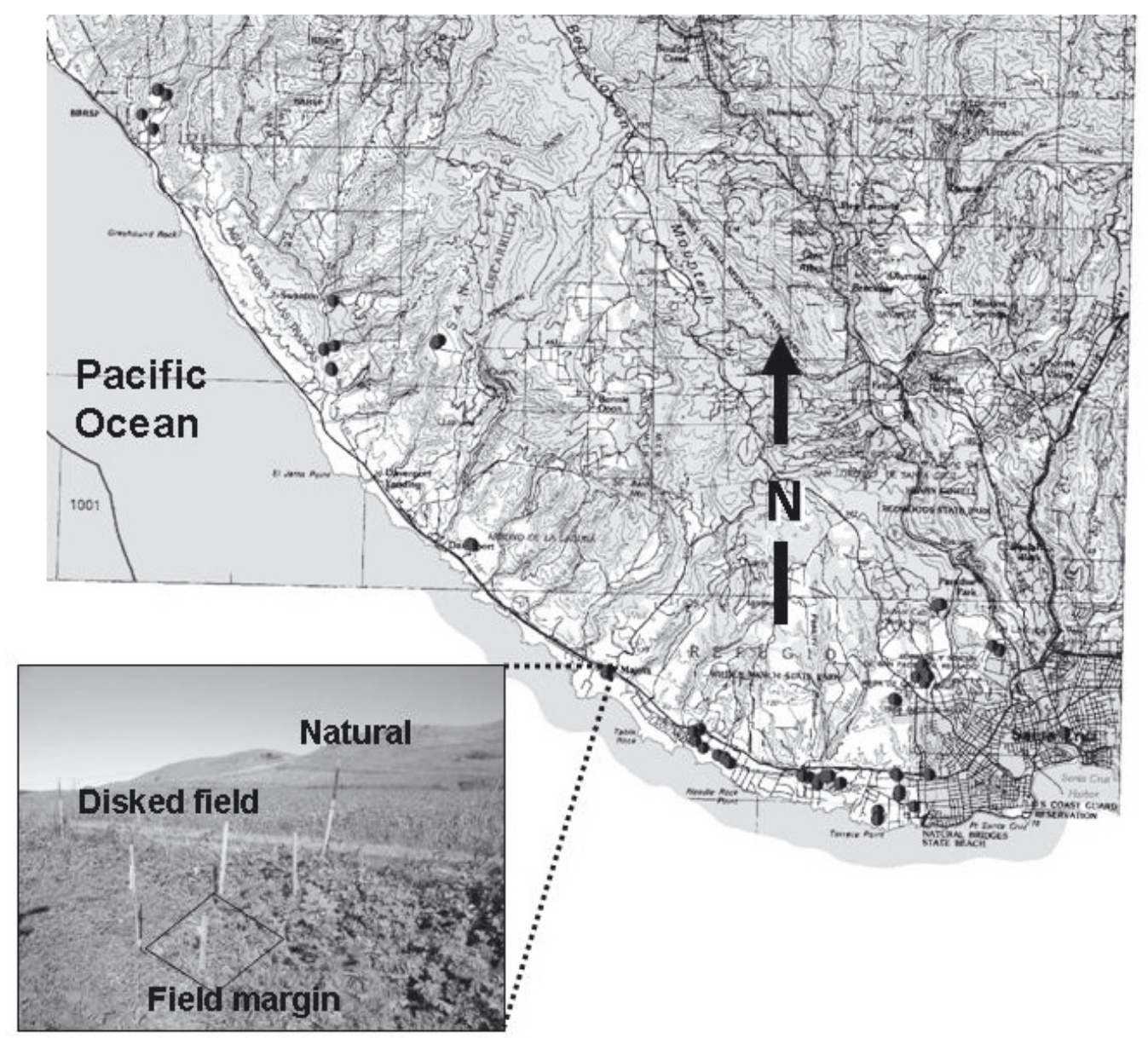

Figure 1. The location of 90 experimental plots (black dots, some plots overlapping) at 30 sites (used in 2004-2006) along the central coast region of California, north and northwest of the city of Santa Cruz, the southern most site used in 2003-2004, the western and eastern halves of the plots (separated with the north arrow), and habitat types at a single western site (expansion photograph with CA state park land in background, a broccoli field, and roadside/field margin in the foreground) with a $1 \mathrm{~m} \times 1 \mathrm{~m}$ field margin plot demarcated by wooden stakes in the photograph.

Although there was no overall significant effect of herbivory on seedling survivorship in 2004-2005, exposure to $B t$-susceptible herbivores resulted in a faster decline in the western half of the plant population (Fig. 2A; SAS-PHreg, Likelihood Parameter estimates, $\mathrm{X}^{2}=4.1$, df $=1, P=0.0430$ for treatment and $P>0.05$ for habitat), which tended to suffer greater levels of herbivore damage than did plants in the eastern plots (Fig. 2B; no significant difference for either herbivory or habitat). The hazard ratio indicated a $28.5 \%$ decrease in the probability of dying when a plant was sprayed with Bt. In 20052006 , exposure to $B t$-susceptible herbivores resulted in a faster decline in the plant population (Fig. 3A; SASPHreg, Likelihood Parameter estimates, $\mathrm{X}^{2}=9.8, \mathrm{df}=1$, $P=0.0017$ for treatment) than did protection with $B t$ sprays, and survivorship was lowest in natural vegetation
(Fig. 3B; $\mathrm{X}^{2}=12.0, \mathrm{df}=2, P=0.0005$ for habitat type). Only $15.2 \%( \pm 2.5 \% \mathrm{SE})$ of tracked seedlings lived to reproduce when exposed to $B t$-susceptible herbivores $v s$. $24.2 \%( \pm 3.7 \% \mathrm{SE})$ when protected by $B t$ sprays. Hazard ratios for 2005-2006 indicated a $20.4 \%$ decrease in the probability of dying when a plant was sprayed with $B t$, and a $13.5 \%$ increase in the probability of dying when comparing disked field plots to field margins and again from field margins to natural vegetation.

\section{Seed production}

The average seed production per plant (with prereproductive death of live seedlings resulting in zero seeds for that plant) depended on both the relative amount 

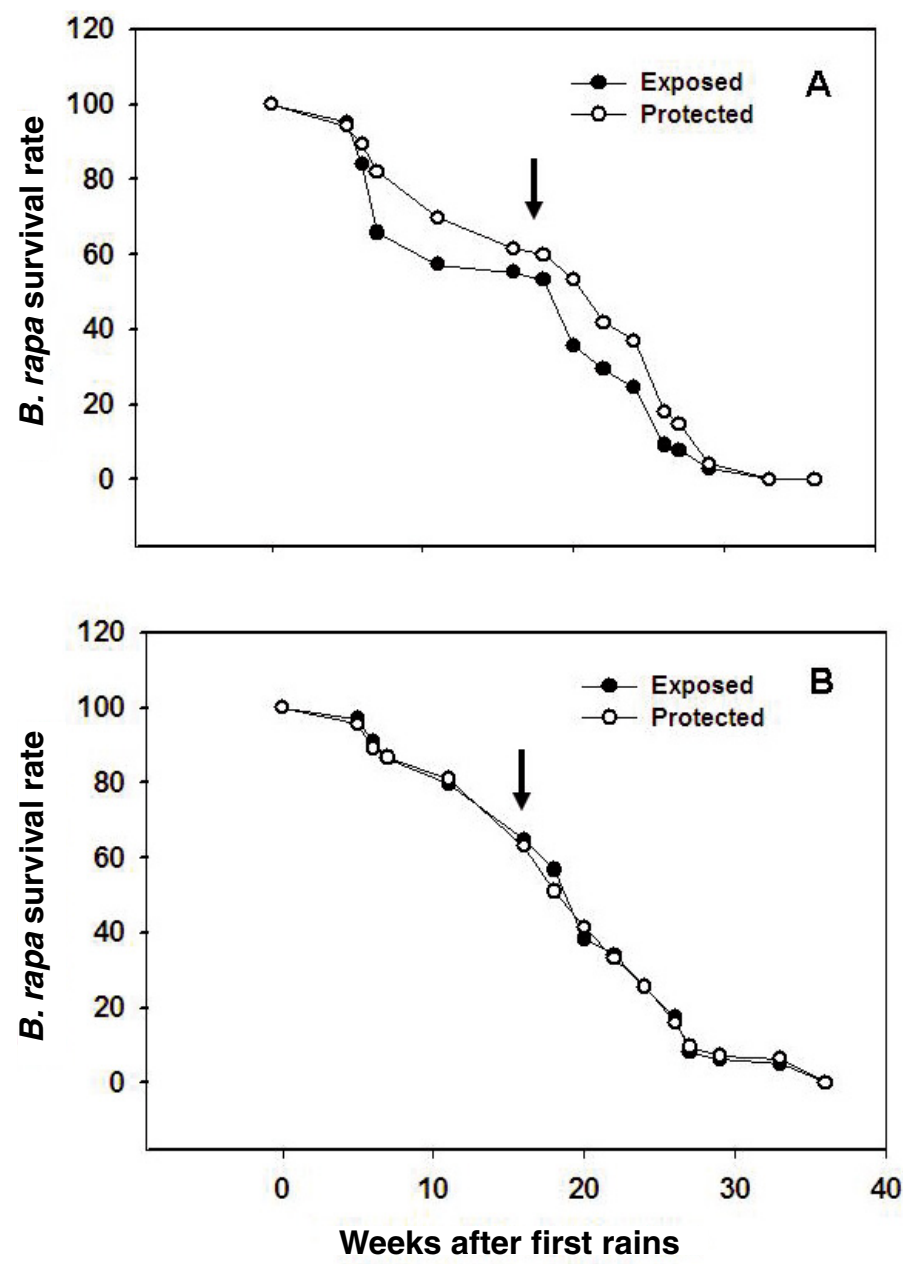

Figure 2. Survivorship curves of $B$. rapa seedlings protected with $B t$ sprays (circles) or exposed to $B t$-susceptible herbivores (dots) in 2004-2005, with mean onset of flowering depicted by arrows, show that (A) in the western population, protected plants had a significantly slower decline (SAS-Lifetest, Wilcoxon Chi-square $=7.0, P=0.0081$ ) than did plants exposed to $B t$-susceptible herbivores, but (B) the eastern population of B. rapa, which experienced lower herbivore pressure, showed no effect of herbivore treatment.

of herbivory and habitat type. Seed output in the preliminary experiment, which received low levels of herbivory, was relatively low overall in 2003-2004, and did not differ between protected and exposed plants (mean of 36 and 35 seeds per initial seedling, respectively). However, in both 2004-2005 and 2005-2006 seed production by $B$. rapa plants was significantly greater when plants were protected with $B t$ sprays than when exposed to $B t$-susceptible herbivores. Seed output per plant was also significantly influenced by both habitat type and site, with no significant interaction between herbivory treatment and habitat type (Tab. 1). In 2004-2005, an average $B t$-protected $B$. rapa plant produced $91.0( \pm 35.7 \mathrm{SE})$ seeds, compared to less than half that many seeds $(39.8 \pm$ $11.5 \mathrm{SE})$ when plants were exposed to $B t$-susceptible herbivores (Fig. 4, Tab. 1). Bt-protected B. rapa in 20052006 again produced over twice as many seeds per plant as plants exposed to $B t$-susceptible herbivores (331.0 \pm 40.5 SE compared to $128.4 \pm 19.8$ ). Lowest seed output values were in natural vegetation plots (Tab. 1, Fig. 4). $B$. rapa in natural vegetation plots produced significantly fewer seeds, on average, than did plants in disked field plots in 2004-2005 and fewer seed than plants in either disked or field margin plots in 2005-2006 (Fig. 4).

In a separate comparison of only plants that produced seeds (disregarding all plants that suffered early mortality), herbivory treatment was not a significant factor in 2004-2005 (General Linear Models ANOVA on ranks, $\mathrm{DF}=1137 ; \mathrm{F}=1.4, P=0.2385)$, and $B t$-sprayed plants produced only $26 \%$ more seeds $(164.6 \pm 41.3$ 

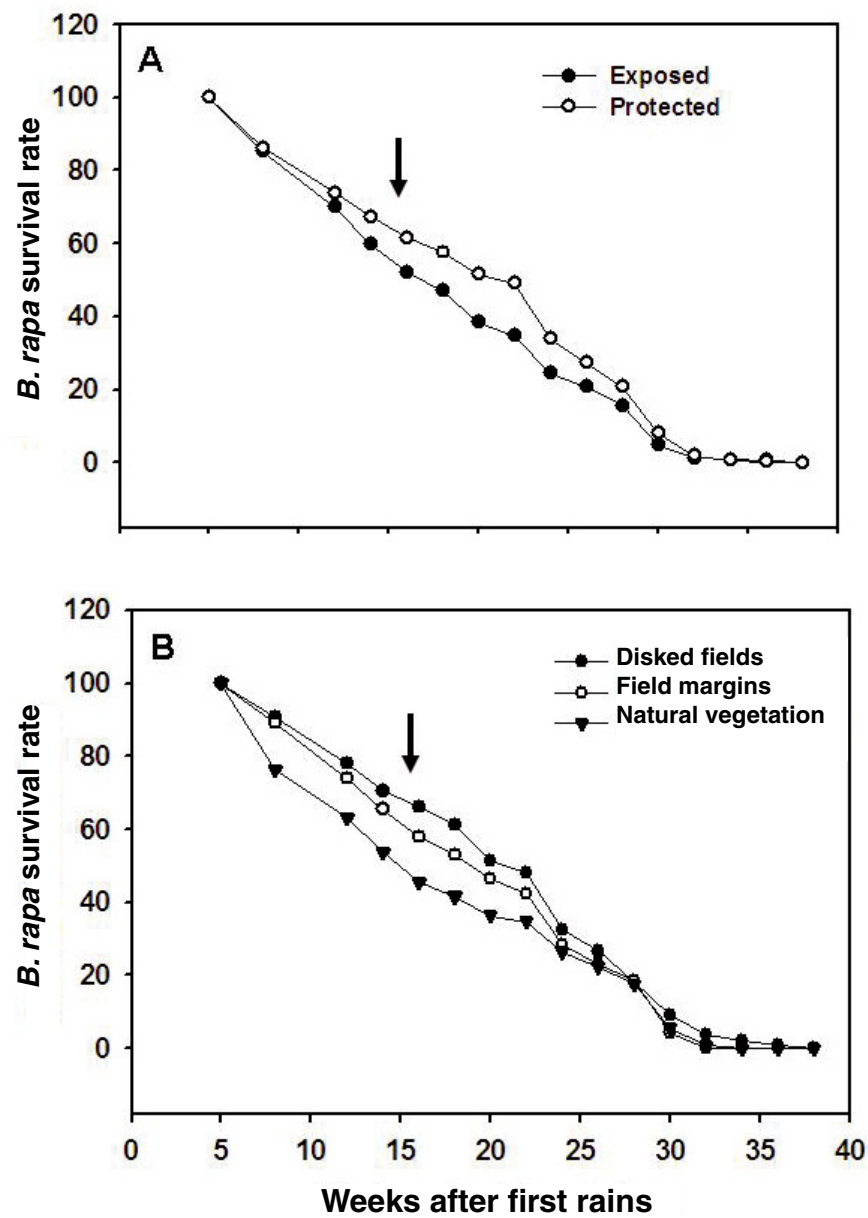

Figure 3. Survivorship curves of B. rapa seedlings in 2005-2006, with mean onset of flowering depicted by arrow, show (A) that plants protected with $B t$ sprays (circles) had a significantly slower decline (SAS-proportional hazards model) than did plants exposed to $B t$-susceptible herbivores (dots), and (B) that B. rapa in natural vegetation (triangles) declined significantly faster than did those growing in disked soil or field margins (dots, circles).

versus $130.6 \pm 39.7)$. In 2005-2006, protected plants that lived produced significantly more seeds per plant $(869.1 \pm$ 94.0 SE) than did exposed plants $(598.1 \pm 96.8 \mathrm{SE})$ that lived (General Linear Models ANOVA on ranked seed output, $\mathrm{DF}=1252 ; \mathrm{F}=12.1, P=0.0006)$, showing a $50 \%$ advantage in seed output. Whether there was (20052006) or was not (2004-2005) a significant increase in seed production per seed-producing plant, early mortality explained a substantial amount of the observed increases of 125\% (2004-2005) and 150\% (2005-2006) in lifetime fitness due to relaxed herbivory on protected plants.

\section{DISCUSSION}

Our field experiments show that the decrease in herbivore damage expected after gene flow from Bt Brassica crops (B. napus or B. oleracea) to B. rapa is likely to result in greater plant survivorship, fecundity, and, in the aggregate, an increase in plant fitness compared to an equivalent population that is not protected by a $B t$-based resistance trait. As a selective resistance trait, $B t$ toxins reduce plant feeding by some, but not all of the insect herbivores that feed on $B$. rapa. Although $B t$ toxins are effective against several target lepidopteran crop pests, most of the 52 species of lepidopterans recorded as feeding on $B$. rapa worldwide have not been tested for susceptibility to Bt Cry proteins (Letourneau et al., 2003). Some foliar tissue removal was commonly present on protected B. rapa (45\% and $61 \%$ of $B t$-sprayed plants damaged in 2004-2005 and 2005-2006, respectively), suggesting that consumers included species that were not susceptible to $B t$ toxins. Although wild mustard exhibits some aspects of ecological release when protected from 
D.K. Letourneau and J.A. Hagen

Table 1. General linear models ANOVA on rank-transformed seed counts per seedling shows significant effects of herbivory $($ tmt $=$ protected or exposed), habitat type (hab = disked field, field margin, natural vegetation), and site (location) on lifetime fitness of B. rapa, but no significant difference between seedlings and replacement transplants (Stype).

\begin{tabular}{lcccrr}
\hline Source (2004-2005) & DF & Type III SS & Mean square & F-value** & $P$-value \\
\hline Site & 29471 & 1478957.410 & 50998.531 & 4.79 & $<0.0001$ \\
Hab & 256 & 221602.3585 & 110801.1792 & 4.38 & 0.0170 \\
site*hab & 56471 & 1415221.021 & 25271.804 & 2.38 & $<0.0001$ \\
Tmt & 1471 & 88125.550 & 88125.550 & 8.28 & 0.0042 \\
tmt*hab & 2471 & 27124.847 & 13562.423 & 1.27 & 0.2805 \\
\hline Source (2005-2006) & \multicolumn{5}{c}{} \\
\hline Stype & 1908 & 4016.91 & 4016.91 & 0.16 & 0.6886 \\
Site & 26908 & 18839101.25 & 724580.82 & 28.98 & $<0.0001$ \\
Hab & 248 & 583418.2217 & 291709.1109 & 5.64 & 0.0063 \\
site*hab & 48908 & 2482112.55 & 51710.68 & 2.07 & $<0.0001$ \\
Tmt & 1908 & 1229651.08 & 1229651.08 & 49.19 & $<0.0001$ \\
stype*hab & 2908 & 17372.78 & 8686.39 & 0.35 & 0.7066 \\
stype*tmt & 1908 & 11353.00 & 11353.00 & 0.45 & 0.5005 \\
tmt*hab & 2908 & 55046.70 & 27523.35 & 1.10 & 0.3330 \\
stype*tmt*hab & 2908 & 85821.01 & 42910.50 & 1.72 & 0.1803 \\
\hline
\end{tabular}

** Using Type III sums of squares and site*hab as the error term for hab.

the $B t$-susceptible subset of its herbivores, the effect of reduced herbivory was less pronounced in non-agricultural areas, where plant-plant competition was likely to be the strongest factor affecting seed production. Meadows and ruderal habitats tended to have well-established perennial vegetation, including grasses, which grew rapidly at the onset of winter rains.

Our study is one of the few contributions to date that were designed to investigate plant fitness consequences of $B t$-based insect resistance traits on wild plants (Moon et al., 2007; Ramachandran et al., 2000; Snow et al., 2003; Stewart et al., 1997; Sutherland et al., 2006; Vacher et al., 2004). While all contribute useful information for identifying potential hazards for risk assessment, none is wholly ideal. For a given IR crop, an ideal experiment to quantify risk of weediness in populations of crop-weed hybrids would test a wide range of backcrossed, transgenic hybrids (within and among species crosses) to incorporate the natural genetic variation and potential genetic linkage effects resulting from spontaneous crosses in natural conditions. Such an experiment would be replicated sufficiently to detect differences, and carried out in a range of geographic locations and conditions at sites with naturally-occurring populations of wild relatives. Herbivore damage, pollination, and plant-plant competition levels would be quantifiable co-variates, and span the range of natural occurrence across space and time in accessible environments. Plant fitness (male and female) and population demography over time would be followed by tracking plants and their offspring using molecular markers and gauging the effect of the IR trait on subsequent population growth rates and other parameters of invasiveness. Due to the scope and the requirements for non-isolated, uncontained releases, the ideal experiment for a given IR crop, then, is not possible. Instead, researchers have worked within methodological constraints imposed by the need for containment.

Each currently available study on fitness responses to herbivory for $B t$ plants has differed in its approach, and has had a unique set of strengths and limitations built into the methodological choices employed. For example, Moon et al. (2007) measured seed output for multiple $B t$ crop-wild hybrids from different weedy accessions. Vacher et al. (2004) included the observed range of plant densities in a factorial experiment with herbivory. Most studies have demonstrated a statistically significant increase in seed output when plants were protected from $B t$-susceptible herbivores. Snow et al. (2003) found greater seed set on male-sterile, transgenic $B t$ sunflower than for a non-transgenic isoline. Stewart et al. (1997) and Ramachandran et al. (2000) measured significant increases in seed output in transgenic oilseed rape exposed to diamondback moth larvae in field trials, tented field trials, and greenhouse experiments. Sutherland et al. (2006) did not find a plant fitness effect when only cotyledons were damaged (mechanically) of $B$. napus $\times B$. rapa hybrids and their parental plants. In the first study using transgenic Bt B. rapa and $B$. rapa $\times B$. napus hybrids (with and without the $B t$ transgene), Moon et al. (2007) demonstrated significantly higher seed output in greenhouse conditions with herbivore additions, but no effect in field trials with low ambient herbivory levels. Taken together, these studies suggest that moderate to high herbivore damage produces an increased plant fitness consequence of $B t$-based plant protection. 

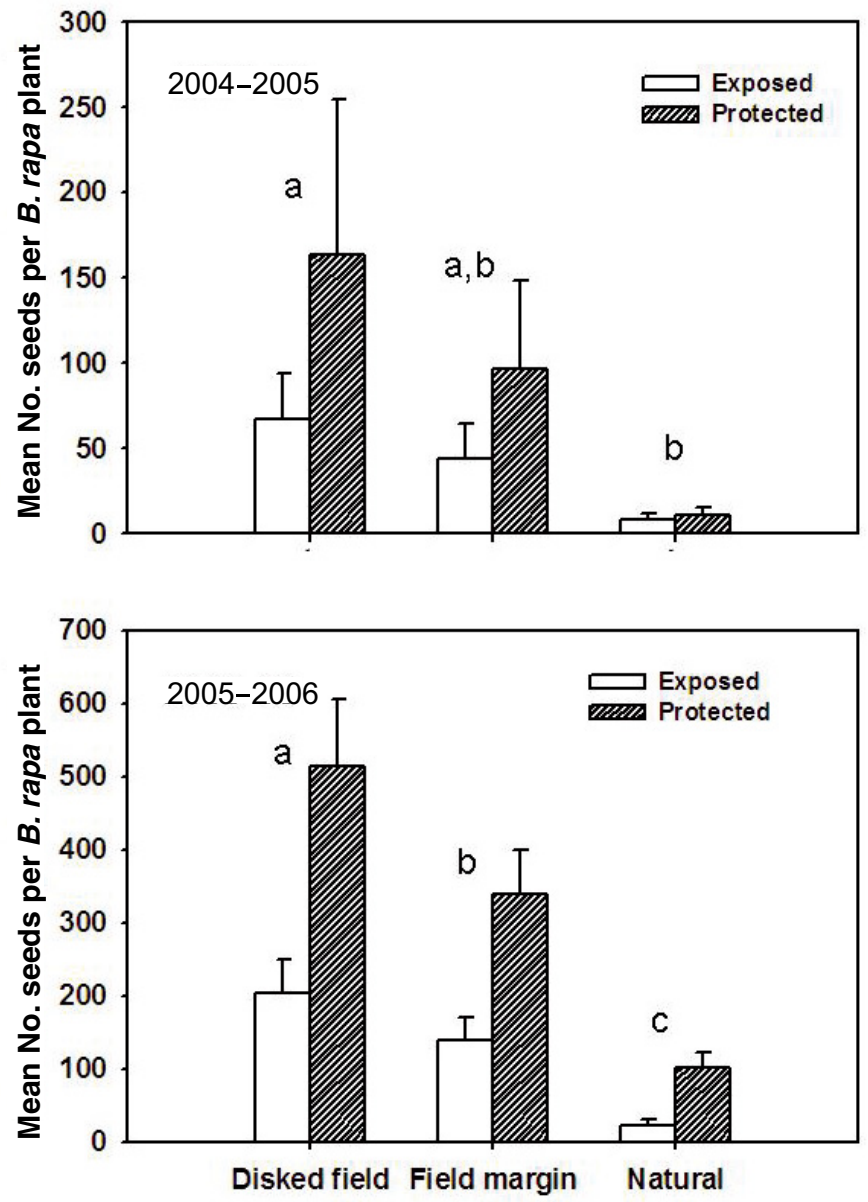

Figure 4. In both 2004-2005 (A) and 2005-2006 (B) B. rapa plants protected with Bt sprays produced significantly more seeds (mean \pm standard error) than did plants exposed to $B t$-susceptible herbivores, but also produced significantly more seeds when growing in disked soil or field margins than in natural vegetation (for each year, different letters for significant differences among habitats, Duncan's means separation test, $P<0.05$ ).

Interpreting the results of available studies for scientifically based risk assessment of IR trait escape to wild relatives involves exploring any potential limitations inherent in the methodologies. In our study, the use of $B t$ sprays on parental wild plants does not allow for compromising fitness aspects that may come into play with genetic load from $B t$ transgenes or crop genes, especially in the initial hybrid formation and early backcross stages. Although Mason et al. (2003) found no fitness cost of the $B t$ transgene in wild B. napus, and Moon et al. (2007) (whose accessions included wild mustard from California) found no reduction in seed output in $B t$ crop-wild hybrids as compared to wild $B$. rapa, Halfhill et al. (2005) measured substantially lower seed output in crop-wild hybrids derived from B. rapa accessions from Quebec. Also, Vacher et al. (2004) detected fitness depression from crop genes, but $B t$ protection in the presence of herbivores compensated through a net increase in seed output of hybrids. Therefore, the impact of $B t$ transgenes on mortality and fecundity of $B$. rapa hybrids and backcrossed individuals will depend on any fitness cost due to linked crop genes or the identity of the wild population, on the kind and how much herbivory the plant would have normally sustained, and on the surrounding habitat conditions, especially plant-plant competition. However, the potential for increased fecundity and subsequently higher rates of spread of wild plants with added protection against herbivores has been upheld in field experiments, whether those experiments were performed using naturally occurring wild relatives with herbivore manipulations or with transgenic $B t$ plants.

Researchers and regulators involved in risk assessment face data gaps when it comes to predicting the consequences of host plant resistance genes escaping 
into wild plant populations (Hoffman, 1990; Marvier and Kareiva, 1999; Snow et al., 2005). Tiered frameworks for risk assessment (e.g. Andow and Zwahlen, 2006) are designed to reach an informed prediction of the likelihood that harm will occur from an action, using the minimal amount of data. Using the framework proposed by Raybould and Cooper (2005), tests for a fitness advantage associated with $B t$-based resistance in wild plants constitute a 1st tier hazard assessment (or a 2nd tier hazard assessment if 1 st tier involves only potential hybrid formation). The flexibility of herbivore exclusion experiments such as ours using wild B. rapa is compelling despite potential trade-offs of this method. That is, factors such as hybrid fertility and vigor, hybrid seed emergence, differences between transgene expression and topical sprays (issues from genetic load to toxicity range on herbivores), and the competitiveness of the $\mathrm{F} 1$ and backcross generations (e.g. Allainguillaume et al., 2006; Ammitzboll et al., 2005; Halfhill et al., 2005) could partially mitigate or exacerbate any undesirable outcome of host plant resistance traits (Raybould and Cooper, 2005). One advantage of herbivore exclusion tests, at an early step in a risk assessment process, designed to determine the likelihood of increased weediness in crop-weed hybrids with introgressed plant defense transgenes, is that the tests can be carried out in the regions, habitats and conditions (native soils, pollinators, herbivores) where hybrids are likely to form. Another advantage is that transgenic constructs of different wild relatives are not necessary, so limits and artifacts involving genetic variability and position effects are avoided. Assessing the potential for increased weediness of plant species with novel traits in different habitats is critical, given the economic and environmental consequences (Hilbeck, 2001; Randall, 1996). Therefore, herbivore exclusion experiments are useful tools for predicting potential effects of a range of insect resistance traits on the population dynamics of crop relatives that may receive these traits through gene flow from transgenic crops.

\section{MATERIALS AND METHODS}

\section{Plants and crop-wild gene flow}

Wild mustard (Brassicaceae: Brassica rapa L.) is a naturalized winter annual in California that germinates in October or November with the first rains and produces seed in spring. This plant is a self-incompatible, insectpollinated weed with persistent seed banks (Warwick and Stewart, 2005). Although wild mustards grow interspersed with and surrounding Brassica crops in California (Santa Cruz and Monterey counties produce 75000 acres of Brassica crops in a mosaic of landuses including coastal natural reserves for biodiversity conservation), the likelihood that $B t$ traits from insect resistant oilseed rape, broccoli, or cabbage, if grown in our region, would transfer to local wild mustard is difficult to measure. Pollen transfer is likely for flowering oilseed rape and also possible for vegetable crop fields (broccoli and cabbage), where there can be occasional early flowering individuals, post-harvest remnant flowering plants, early bolting or unharvested fields, and flowering foundation seed crops. Oilseed rape (B. napus) readily hybridizes in the field with B. rapa (FitzJohn et al., 2007; Jorgensen and Andersen, 1994; Warwick et al., 2003), and $B t$ transgenes are stably expressed in these crop-wild hybrids (Zhu et al., 2004). Crosses between B. oleracea and wild relatives have been much less studied, so it is difficult to determine a probability of spontaneous hybridization with wild relatives in the field beyond its apparent compatibility with naturalized $B$. oleracea in our region (Letourneau et al., 2002). In cases where spontaneous, fertile hybrid formation is rare, the likelihood of introgression depends primarily upon the level of exposure (number of flowering crop plants in this cole crop producing region over time and space).

\section{Study sites and experimental design}

Thirty experimental field sites, representing a range of historical land uses, dominant vegetation, and local climate conditions, were located in 2004 in the coastal region north and west of Santa Cruz, California $\left(36.974^{\circ} \mathrm{N}\right.$, $-122.029^{\circ} \mathrm{W}$ ), a region with a Mediterranean climate where $0.78 \mathrm{~m}$ annual precipitation falls between October and May. At each site, we established three $1 \mathrm{~m} \times$ $1 \mathrm{~m}$ experimental plots, with one third of the plots per site designated for each of the three habitat types: disked agricultural fields, agricultural field margins, and undisturbed, natural vegetation (Fig. 1). Disked field plots, located $\leqslant 5 \mathrm{~m}$ from row crops, were dug with a shovel to turn over $10-20 \mathrm{~cm}$ of soil to simulate disking and disrupt any vegetation formerly occurring on that plot. Field margin plots were not disturbed, had weedy vegetation, and were often on soil compacted by farm machinery. Both disked field and field margin plots were exposed to rain and irrigation run-off from fertilized fields (downhill placement from adjacent crop fields). Natural vegetation plots were established in meadows and ruderal areas near crop fields, had a mixture of naturally occurring native and exotic plants, and received no run-off or irrigation.

Each plot was split to impose herbivory treatments (exposed and protected). Before the first rain, approximately 30 mustard seeds from 10 mother plants were added to each subplot. We re-seeded subplots after 10 days if fewer than six seedlings of the seeded plant species emerged. In 2005-2006, we transplanted mustard seedlings as needed, using seedlings found growing 
nearby our experimental plots (also emerging at the first rains, and from the local bank) to establish four to eight seedlings per subplot. By adding either seed or transplants, we were able to follow B. rapa seedlings in all 90 $1 \mathrm{~m} \times 1 \mathrm{~m}$ plots (and their subplots) in both years until death or senescence.

\section{Herbivory treatment}

Three weeks after the first rains in fall 2004, four plants per subplot were numbered individually, and herbivory treatments were applied (active $B t$ spray or denatured $B t$ spray plus one 1 st or 2 nd instar Pieris rapae larva). Plants to be protected from $B t$-susceptible herbivores, including diamondback moths (Plutella xylostella L.), cabbage loopers (Trichoplusia ni L.), and cabbage butterflies (Pieris rapae L.), received a drenching spray of active $B t$ (1 g Dipel ${ }^{\circledR}$ Dry Flowable (DF) powder per $750 \mathrm{~mL}$ of de-ionized $\mathrm{H}_{2} \mathrm{O}$ with a potency of $32000 \mathrm{Cab}$ bage Looper Units (CLU) per mg). Active $B t$ spray does not protect these plants from other herbivores, including cabbage aphids (Brevicoryne brassicae L.), green peach aphids (Myzus persicae L.), flea beetles (Phyllotreta cruciferae L.), slugs, and snails. Plants to be exposed to herbivory by the whole complement of herbivores were sprayed weekly with a suspension of deactivated $B t(1 \mathrm{~g}$ Dipel ${ }^{\circledR}$ DF per $750 \mathrm{~mL}$ of de-ionized water, denatured by high heat in an autoclave). Sprays were repeated at weekly intervals and $P$. rapae larval additions (reared in our greenhouse from field-collected individuals) were applied monthly in 2004-2005 (resulting in a total of 12 larvae added per plant) and every 3-4 weeks in 20052006 for a maximum of three larvae per plant over the season. Larval addition rates were based on counts of lepidopteran eggs throughout a three month period on $B$. rapa in a previous, non-outbreak year for $P$. rapae (Letourneau and Fox, unpublished data).

In a preliminary experiment at our southern most field margin site (Fig. 1) in 2003-2004, 81 wild mustard plants ( $n=36$ exposed, with 1-2 larval additions over the season and $n=45$ protected with $B t$ sprays) were evaluated for defoliation rates. Herbivore pressure was categorized on 12-week-old plants according to the amount of tissue removed on each plant leaf as $0(=0 \%), 1(=1-25 \%)$, $2(=25-50 \%)$, or $3(>50 \%)$, for a mean estimate per plant. In 2004-2005, we estimated percent herbivory per seedling at week 8 (using refined categorical estimates $0=0-4 \%, 1=5-15 \%, 2=16-25 \%, 3=26-50 \%$, $4 \geqslant 50 \%$ ). In each year, plant status (rosette, bolting, budding, flowering, producing siliques or pods, or dead) was recorded biweekly until all living plants had produced their seed crop. In 2004-2005, plant status was recorded on two of the four plants at week 15 after the rains. In 2005-2006, we followed at least four plants per subplot. Seeds were collected multiple times from each plant as siliques matured in spring to avoid seed loss due to the shattering of the silique after drying. The total number of viable mustard seeds per plant was determined by counting all seeds (2003-2004) or by weighing 30 seeds per plant, and estimating the total number of seeds for that plant by weighing the remaining seeds (2004-2005, 2005-2006).

$B t$ sprays have been used successfully to test for the likelihood of $B t$ resistance and to mimic transgenic $B t$ effects in various studies (Delannay et al., 1989; Gould, 1988; Riggin-Bucci and Gould, 1997; Tabashnik et al., 1990). Weekly topical $B t$ sprays may underestimate the strength of actual $B t$ gene expression, which affects plant tissues through persistent, constitutive expression of $B t$ toxins. However, topical $B t$ spray (Dipel ${ }^{\mathbb{R}}$ Dry Flowable (DF) powder, Safer ${ }^{\circledR}$, Caterpillar Killer $\left.{ }^{\circledR}\right)$, is highly effective against $P$. rapae, which ceased movement and feeding shortly after contacting sprayed tissue in greenhouse observations, laboratory trials with cabbage leaf disks, and field tests with Raphanus sativus (Letourneau and Hagen, unpublished data). In all cases, denatured $B t$ (proteins destroyed in an autoclave) showed no effect. We used denatured $B t$ as a control for the topical application of $B t$ sprays because plants exposed to herbivory then have the same experience of being sprayed with water and bacterial material. Because active $B t$ spray rapidly prevents feeding and causes death to the larvae we added to plants, plants protected through repeated applications of active $B t$ were not inoculated with $P$. rapae larvae in the large scale field experiments reported here.

\section{Data analyses}

All analyses used PC-SAS v. 9.1 (SAS Institute Inc., 2004). Logistic regression was used to test for significant differences in herbivory (assigning the mid-point percent herbivore damage for each category to arrive at mean percent herbivory, for example 5-15\% damage was assigned the value $10 \%$ ) between the protected and control plants in 2004-2005. Seed output per plant was compared using all plants in 2004-2005. In 2005-2006, we used all plants germinated from seed as in 2004-2005 plus the plants transplanted to plots that had fewer than four plants germinate from seed. However, failed transplants that died within two weeks and late transplants (several plants added after week 8) were dropped from the analysis. Both failed transplants and late transplants were not reliable indicators of treatment effects due to minimal exposure to treatments early in the season. In both years, we used Generalized Linear Models-ANOVA on ranked seed ouput values (because neither seed output for all plants, which included many zeroes for plants that died as seedlings nor seed output for plants that lived 
to produce seeds were normally distributed) to analyze for effects of herbivory treatment (tmt $=2$ levels, protected and exposed), habitat type (hab $=3$ levels, disked fields, field margins, and natural vegetation), and any interaction between treatment and habitat type. Because herbivore treatment was a split plot within the main effect of habitat type, the error term for testing for differences among habitat types was the site*habitat type interaction. In 2005-2006, we added a transplant factor (2 levels, seed or transplant) to check for potential confounding effects of that variable.

Using separate analyses for 2004-2005 and 20052006, we compared survivorship of marked seedlings with respect to herbivory treatment $(\mathrm{tmt}=2$ levels, protected and exposed) and habitat type (hab $=3$ levels, disked fields, field margins, and natural vegetation) with the PHreg procedure (semiparametric, proportional hazards model for censored data, suited for discrete values for plant survival time organized as a lifetable), stratifying for herbivory treatment and habitat type (Allison, 1995). Plant data were right-censored at 36 weeks, when all B. rapa were dead or with dried siliques. Survivorship curves were generated using output from SAS-Lifetest analyses. In 2004-2005, we examined the eastern and western halves of the experimental plots separately due to greater herbivore pressure on the western plots (Fig. 1). We used a logistic regression to compare categorically, values of seedling mortality by herbivory treatment (two levels: protected = activated $B t$ sprays, no caterpillar additions vs. exposed $=$ deactivated $B t$ sprays, caterpillar addition) and habitat type (three levels: disked field, field margin, and natural vegetation).

\section{ACKNOWLEDGEMENTS}

This research was supported by USDA Biotechnology Risk Assessment Grant 2003-33120-13968, faculty research grants from the UCSC Academic Senate and Social Sciences Division, and graduate student fellowship and research grants from the National Science Foundation and UCSC Department of Environmental Studies. We thank the UCSC Center for Agroecology and Sustainable Food Systems, UCSC Natural Reserves system, and California State Parks for permission to establish test plots, J. Velzy for greenhouse access, and several local growers and land managers for access to field sites and logistical assistance. We thank I. Parker for help with experimental design and logistical dilemmas, and T. Roubison for rearing larvae and field assistance. S. Bothwell, A. Zeilinger, R. Abarca, D. Barrantes, L. Barth, S.L. Bryan, C. Conlan, E. Encarnacion, A. Fintz, L. Funk, E. Hampson, E. Hariton, F. Hesse, C. Josephson, A. LeComte, J. Martin, S. Moskal, R. Muscutt, Y. Pellman,
T. Rogers, A.H. Stroud, A. Warner, and J. Wilson assisted in conducting field and lab experiments.

Received April 30, 2008; accepted November 18, 2008.

\section{REFERENCES}

Allainguillaume J, Alexander M, Bullock JM, Saunders M, Allender CJ, King G, Ford CS, Wilkinson MJ (2006) Fitness of hybrids between rapeseed (Brassica napus) and wild Brassica rapa in natural habitats. Mol. Ecol. 15: 11751184

Allison PD (1995) Survival analysis using SAS ${ }^{\circledR}$ : A practical guide. Cary, NC: SAS Institute Inc., 292 p

Ammitzboll H, Mikkelsen TN, Jorgensen RB (2005) Transgene expression and fitness of hybrids between GM oilseed rape and Brassica rapa. Environ. Biosafety Res. 4: 3-12

Andow DA, Zwahlen C (2006) Assessing environmental risks of transgenic plants. Ecol. Lett. 9: 196-214

Clark EA (2006) Environmental risks of genetic engineering. Euphytica 148: 47-60

Colwell RK, Norse EA, Pimentel D, Sharples FE, Simberloff D (1985) Genetic engineering in agriculture. Science 229: 111

Darmency H (1994) The impact of hybrids between genetically modified crop plants and their related species: Introgression and weediness. Mol. Ecol. 3: 37-40.

Delannay X, LaVallee B, Proksch R, Fuchs R, Sims S, Greenplate J, Marrone PG, Dodson RB, Augustine JJ, Layton JG, Fishhoff D (1989) Field performance of transgenic tomato plants expressing the Bacillus thuringinesis var. kurstaki insect control protein. Bio/technology 7: 1265-1269

Ellstrand NC (2003) Dangerous liaisons?: when cultivated plants mate with their wild relatives, Johns Hopkins University Press, Baltimore

Ellstrand NC, Prentice HC, Hancock JF (1999) Gene flow and introgression from domesticated plants into their wild relatives. Annu. Rev. Ecol. Syst. 30: 539-563

FitzJohn RG, Armstrong TT, Newstrom-Lloyd LE, Wilton AD, Cochrane M (2007) Hybridisation within Brassica and allied genera: evaluation of potential for transgene escape. Euphytica 158: 209-230

Gould F (1988) Evolutionary biology and genetically engineered crops. BioScience 38: 26-33

Hails RS (2000) Genetically modified plants - the debate continues. TREE 15: 14-18

Hails RS, Morley K (2005) Genes invading new populations: a risk assessment perspective. TREE 20: 245-252

Halfhill MD, Sutherland JP, Moon HS, Poppy GM, Warwick SI, Weissinger AK, Rufty TW, Raymer PL, Stewart CN (2005) Growth, productivity, and competitiveness of introgressed weedy Brassica rapa hybrids selected for the presence of Bt cry1Ac and gfp transgenes. Mol. Ecol. 14: 3177-3189 
Hilbeck A (2001) Implications of transgenic, insecticidal plants for insect and plant biodiversity. Persp. Plant Ecol. Evol. Syst. 4: 43-61

Hoffman CA (1990) Ecological risks of genetic engineering of crop plants: scientific and social analyses are critical to realize benefits of the new techniques. BioScience 40: 434

Jorgensen RB, Andersen B (1994) Spontaneous hybridization between oilseed rape (Brassica napus) and weedy Brassica campestris (Brassicaceae) - a risk of growing geneticallymodified oilseed rape. Am. J. Bot. 81: 1620-1626

Kareiva P, Morris W, Jacobi CM (1994) Studying and managing the risk of cross-fertilization between transgenic crops and wild relatives. Mol. Ecol. 3: 15-21

Letourneau DK, Hagen JA, Robinson GS (2002) Bt-crops: Evaluating benefits under cultivation and risks from escaped transgenes in the wild. In Letourneau DK, Burrows BE, eds, Genetically Engineered Organisms: Assessing Environmental and Human Health Effects, CRC Press, Boca Raton, Florida

Letourneau DK, Robinson GS, Hagen JA (2003) Bt crops: Predicting effects of escaped transgenes on the fitness of wild plants and their herbivores. Environ. Biosafety Res. 2: 219246

Marvier M, Kareiva P (1999) Extrapolating from field experiments that remove herbivores to population-level effects of herbivore-resistant transgenes. Workshop on Ecological Effects of Pest Resistance Genes in Managed Ecosystems, Information Systems for Biotechnology, Bethesda, Maryland, pp 57-64

Mason P, Braun L, Warwick SI, Zhu B, Stewart CN Jr (2003) Transgenic Bt-producing Brassica napus: Plutella plutella selection pressure and fitness of weedy relatives. Environ. Biosafety Res. 2: 263-276

Moon HS, Halfhill MD, Good LL, Raymer PL, Stewart CN (2007) Characterization of directly transformed weedy Brassica rapa and introgressed B. rapa with Bt cry1Ac and gfp genes. Plant Cell Rep. 26: 1001-1010

National Research Council (2002) Environmental Effects of Transgenic Plants. National Academy of Sciences, Washington, DC

Parker IM, Kareiva P (1996) Assessing the risks of invasion for genetically engineered plants: Acceptable evidence and reasonable doubt. Biol. Cons. 78: 193-203

Ramachandran S, Buntin GD, All JN, Raymer PL, Stewart CN (2000) Intraspecific competition of an insect-resistant transgenic canola in seed mixtures. Agron. J. 92: 368-374

Randall JM (1996) Weed control for the preservation of biological diversity. Weed Tech. 10: 370-383

Raybould A, Cooper I (2005) Tiered tests to assess the environmental risk of fitness changes in hybrids between transgenic crops and wild relatives: the example of virus resistant Brassica napus. Environ. Biosafety Res. 4: 127-140

Riggin-Bucci TM, Gould F (1997) Impact of intraplot mixtures of toxic and nontoxic plants on population dynamics of diamondback moth (Lepidoptera: Plutellidae) and its natural enemies. J. Econ. Ent. 90: 241-251

SAS Institute Inc. (2004) SAS V.9.1. SAS Institute Inc., Cary, North Carolina, USA

Snow AA, Moran-Palma P (1997) Commercialization of transgenic plants: Potential ecological risks. BioScience 47: 206-206

Snow AA, Pilson D, Rieseberg LH, Paulsen MJ, Pleskac N, Reagon MR, Wolf DE, Selbo SM (2003) A Bt transgene reduces herbivory and enhances fecundity in wild sunflowers. Ecol. Appl. 12: 279-286

Snow AA, Andow DA, Gepts P, Hallerman EM, Power A, Tiedje JM, Wolfenbarger LL (2005) Genetically engineered organisms and the environment: Current status and recommendations. Ecol. Appl. 15: 377-404

Stewart CN, All JN, Raymer PL, Ramachandran S (1997) Increased fitness of transgenic insecticidal rapeseed under insect selection pressure. Mol. Ecol. 6: 773-779

Sutherland JP, Justinova L, Poppy GM (2006) The responses of crop-wild Brassica hybrids to simulated herbivory and interspecific competition: Implications for transgene introgression. Environ. Biosafety Res. 5: 15-25

Tabashnik BE, Cushing NL, Finson N, Johnson MW (1990) Field development of resistance to Bacillus thuringiensis in diamondback moth (Lepidoptera, Plutellidae). J. Econ. Ent. 83: $1671-1676$

Tiedje JM, Colwell RK, Grossman YL, Hodson RE, Lenski RE, Mack RN, Regal PJ (1989) The planned introduction of genetically engineered organisms: ecological considerations and recommendations. Ecology 70: 298

Vacher C, Weiss AE, Hermann D, Kossler T, Young C, Hochberg ME (2004) Impact of ecological factors on the initial invasion of $\mathrm{Bt}$ transgenes into wild populations of birdseed rape (Brassica rapa). Theor. Appl. Genet. 109: 806-814

Warwick SI, Stewart CN (2005) Crops come from wild plants - how domestication, transgenes, and linkage together shape ferality. In Gressel J, ed, Crop Ferality and Volunteerism, CRC/Taylor and Francis, Boca Raton, FL, pp 9-30

Warwick SI, Simard MJ, Legere A, Beckie HJ, Braun L, Zhu B, Mason P, Seguin-Swartz G, Stewart CN (2003) Hybridization between transgenic Brassica napus L. and its wild relatives: Brassica rapa L., Raphanus raphanistrum L., Sinapis arvensis L., and Erucastrum gallicum (Willd.) O.E. Schulz. Theor. Appl. Genet. 107: 528-539

Wolfenbarger LL, Phifer PR (2000) The ecological risks and benefits of genetically engineered plants. Science 290: 2088

Zhu B, Lawrence JR, Warwick SI, Mason P, Braun L, Halfhill MD, Stewart CN, Jr (2004) Inheritance of GFPBt transgenes from Brassica napus in backcrosses with three wild B. rapa accessions. Environ. Biosafety Res. 3: 45-54 